\title{
Innovation Processes - Reference Model, Collaboration via Innovative Zone and Integration into Enterprise Environment
}

\author{
Iveta Zolotová ${ }^{\text {, Peter Kubičko }}{ }^{1}$, Lenka Landryová², and Rastislav Hošák ${ }^{1}$ \\ ${ }^{1}$ Department of Cybernetics and Artificial Intelligence, Technical University Kosice, \\ Letná 9/A, Kosice, the Slovak Republic \\ ${ }^{2}$ Department of Control Systems and Instrumentation, VSB Technical University Ostrava, \\ 17.listopadu 15, Ostrava, the Czech Republic \\ \{iveta.zolotova, rastislav.hosak\}@tuke.sk, \\ peter.kubicko@student.tuke.sk, lenka.landryova@vsb.cz
}

\begin{abstract}
The purpose of the paper is to describe existing possibilities and to propose new possibilities for a permanent improvement of an innovation process as an integral part of the core business processes. This article focuses on the definition and design of the draft reference model of the innovation process as a base for developing a methodology for implementation of an innovation reference process in terms of BPM (Business Process Management) and its related standards. The paper also analyzes the methodology and proposes its implementation in business using a common collaboration area and also an innovation zone. Practical verification of implementing the reference innovation process will be demonstrated by its implementation in a particular organization.
\end{abstract}

Keywords: innovation process, innovation zone, innovation idea, innovation project, innovation information system, process measuring, reference model, model.

\section{Introduction}

Innovation has become an integral element of survival and adaptation to the market situations of each company. It is made possible to focus the company activities, affect the actions, control its core processes in accordance with business processes, and minimize the risk of transactions only with a system approach, which allows the company to constantly work out new and innovative topics and process them to obtain a competitive advantage. Submission and processing of innovative topics into implementable forms shall not be understood as an occasional or exceptional activity of individuals, but presented as a system model adaptable to any business whose future depends on the ability of adaptation. In our article we would like to present a process of innovation with measurable changes of resulting values.

The resulting value of an innovative idea can also be considered a new work experience and verification ideas, which are going to be captured in the form of information arising from the implementation of innovative projects. The systematic processing of ideas and creating an environment for innovation and a process 
innovation in the innovative zone require the selection of an appropriate methodology for processing. After consideration of what is suitable for the company and its environment, since it does not deal with industrial production, but with the supply of IT services, and because of its BPM (Business Process Management) orientation and its project management confirmed by the certificate ISO 9000, it was proposed to design an innovation zone based on business processes, although companies worldwide use other methods to support a systematic approach to innovation process, for example, CREAX, TRIZ, WOIS.

Analyses of the IPA [1]. in European companies showed the following barriers to innovative projects:

- Lack of a systematic methodology - Innovation is often confused with methods for new product development, marketing or simple creative techniques (brainstorming)

- Lack of innovation culture in business

- Not suitable model for managing the innovation process

- Inappropriate methods for generating new solutions - using the method of trial and error

- $\quad$ Lack of knowledge management - up to $70-80 \%$ of the knowledge generated in innovative projects is forgotten or lost.

Neglect of the measurement and evaluation of the benefits of innovation.

\section{Reference Model of an Innovation Process}

The essence of an innovation process reference model is to describe the process with its essential attributes (input, output, resources, rules). This process, however, has a

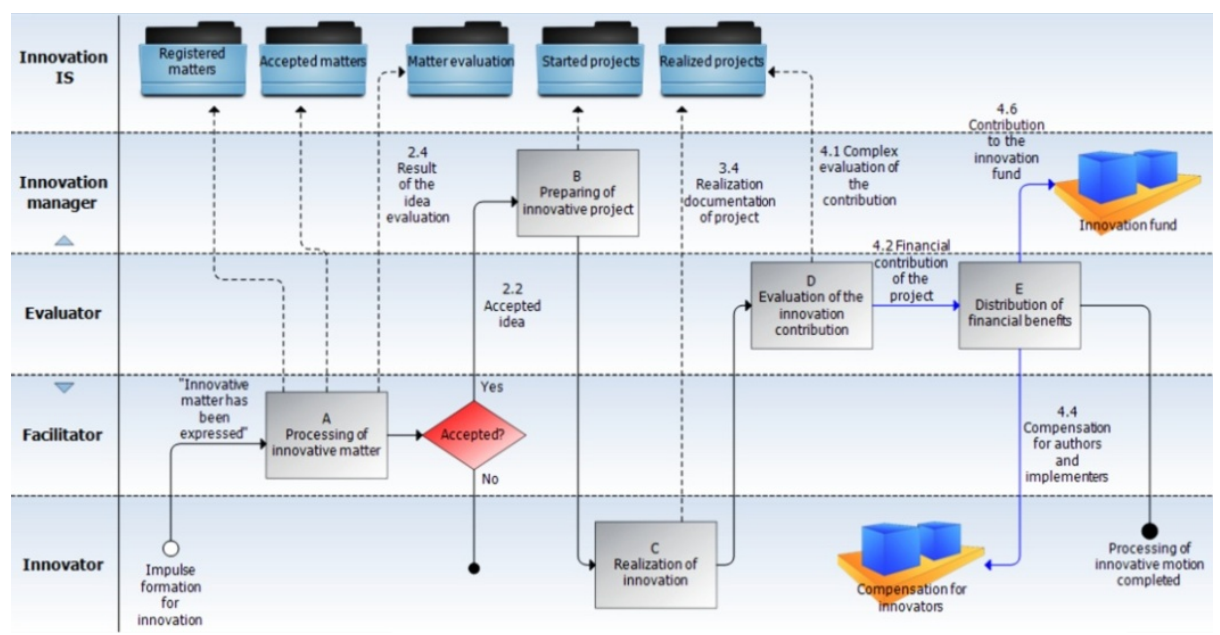

Fig. 1. Innovation process 
special status in a company that is being "protected" by a so called innovative zone, which is supposed to maintain an environment that creates a breeding ground for innovative ideas without prejudging the final outcome.

In a classic business environment mainly profit is monitored at every business activity and in every project, where the loss is unacceptable.

An innovation zone deflects the primary goal of business in the form of making a profit from the innovation process. An innovation process can primarily generate an economic loss, but secondarily creates a potential for future values and the creation of profit.

\subsection{Innovative Zone}

Under the innovation zone it is necessary to understand the limited space of companies in which the innovative zone is implemented (either enterprise, enterprise group or regional or cluster of networking enterprises) with specific management, performance, evaluation and incentive policies. It serves to accelerate innovation in the company. Its role is also in filtering out the impact of the organization, which is under normal conditions resistant to changes that affects adversely especially in the early stages of an innovative project. The innovation zone must be able to meet increased demands for changes in the environment that must be modeled separately, but without compromising the company's standard processes. The innovation zone should have a separate system of financing, planning, monitoring, evaluating the benefits and communication of results of innovative projects. This article presents the idea of implementation the innovation process that is integrated to other business processes using the innovative zone. By introducing an innovation process in the innovation zone the generation of innovative ideas and acceleration of innovative projects can be achieved in a way that does not to interfere with the normal operation of the company, but its results are positively affecting innovative projects. Projects and activities of an innovation zone must improve the company's standard business processes. Results coming from an innovation zone are implemented in standard processes, supported by the top management of a company. Operating costs of innovative zones are minimized by the fact that resources (human, technical, financial) of processes can be shared. The results of an innovation zone are also shared and provided throughout the company. It is important to apply the principle of openness within the company. An innovation zone cooperates with the organizational units of the organization.

The innovative zone thus provides a space where ideas can take root and where they are protected from the effects of organizational inertia as long as they are able to prove their value. The innovative zone also provides an opportunity to implement the ideas of people who are unable to independently transfer their ideas into reality. The innovative zone contains the building blocks necessary for the existence and survival of the zone within which ideas get through the entire process.

The building blocks of an innovative zone are as follow:

- Ownership of ideas

- Evaluation of ideas

- $\quad$ Support of ideas

- Storage of ideas

- Measurement of ideas 
Ownership of Ideas. Ownership of ideas is difficult to accept and maintain if the organization supports an environment and culture where ideas are freely provided, not registered or carefully protected, in considering theft (unauthorized ownership). In organizations, where an innovative zone is successfully used, the owners of the ideas are well respected and rewarded.

Evaluation of Ideas. Ideas that are generated and expressed need to be thoroughly assessed so the owners trust the processes through which ideas will be implemented. Organizations need a set of published values together with examples of successful ideas.

Support of Ideas. It defines the way in which the innovative zone will bring together a team who gives the best opportunity for an idea to evolve and be successful. Supporters of the idea are respected members who facilitate the proper parties to bring an idea to success. For this purpose registration and collaboration tools may be helpful, for example templates and clear rules to protect property rights in the future use of the results of the idea.

Storage of Ideas. It's a place where the ideas, which currently are not required, are stored but can be used in the future. Storage should include all of the historical data from their beginning through their evaluation to reasonable storage to ensure that the selected attributes are available for a possible case use idea.

Measurement of Ideas. It is the process of measuring the value of an idea. It is often regarded as too difficult a task, since many ideas can only be a part of an innovation, or can be directly converted to the currency value. The measurement must be approached in a way so that it will take into account the specific conditions of a business (the needs of relevant ideas and their results), but also the social value and market value. Not every business can have for the same result the same rating scale. Therefore an innovative zone must have available the range of values of the organization in which it is implemented.

The innovative zone ensures that the building blocks exist in the organization and that they are combined into a single process that continuously generates new ideas and filters them.

The creation of the innovative zone in organizations is based on management decisions to build and promote sustainability of the innovative zone in the company. Without the creation of conditions in the form of rules of operation and financing, it can be assumed that it is impossible to build and positively operate the innovative zone in any business. Under positive operation it can be understood that the innovative zone serves the purpose of promoting the capture and evaluation of new ideas in the business of the organization. So decision-making and supporting the innovative zone by management should be embedded in the company's strategy, which is the main framework for the control of all business processes, but the innovative zone must have sufficient competence for processing new ideas so that its operation was not impeded by the effects of other processes. Otherwise, there will be a slowdown and the owners will lose their interest. 
An innovation zone is an area that can be compared to a catalyst for new ideas. To effectively fulfill this role, it must be accepted by the surroundings, but it needs to consist of all the necessary instructions, templates, adequate budgets and skills of participating managers accelerating its own submission, evaluation and verification, as well as collaboration of its participants.

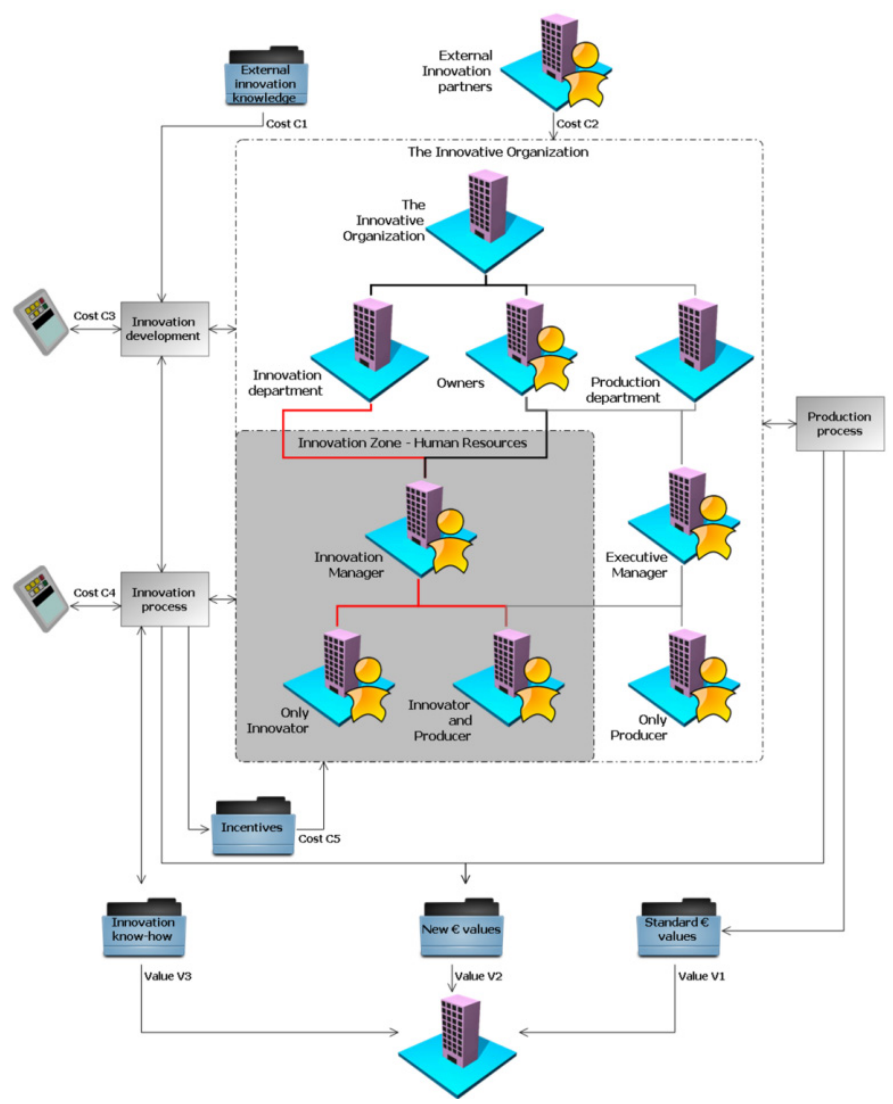

Fig. 2. The model of an innovation organization with innovative zone. $\mathrm{C}-\mathrm{Cost}$, the total cost of innovation is a sum of $\mathrm{C} 1, \mathrm{C} 2, \mathrm{C} 3, \mathrm{C} 4, \mathrm{C} 5$ costs, $\mathrm{C}=\mathrm{C} 1+\mathrm{C} 2+\mathrm{C} 3+\mathrm{C} 4+\mathrm{C} 5$, where $\mathrm{C} 1-$ cost of access to external sources of innovation know-how, $\mathrm{C} 2$ - cost of including external partners into collaboration, C3 - cost of innovation development, C4 - cost of innovation process operation, $\mathrm{C} 5$ - cost of ideas, V - Value, added value to innovation is a sum of V1, V2, V3, where $\mathrm{V}=\mathrm{V} 1+\mathrm{V} 2+\mathrm{V} 3$, V1- a standard value expressed in currency which is produced by manufacturing with or without implemented innovations, V2- new values are a combination of a value coming from production and from the innovation process, also expressed in currency, $\mathrm{V} 3$ - the value of knowledge newly emerged during the innovation process (innovation knowhow), but not measured in currency.

External innovation knowledge is an external source of innovative knowledge, the necessary to link the internal sources of knowledge and their confrontation, the maximum utilization of knowledge for the innovation process, respectively. 
External innovation partners are engaged in the innovation process, they have access to the innovative zone and they may be a part of the innovation process in different roles, whether as evaluators or as submitters of ideas.

Innovation development includes all activities related to a promotion of the innovation development of an organization, ensuring resources and training and the acquisition of interests of employees for innovative activities.

The innovation process is owned by an innovative manager who is also in the position to control the innovative zone. An idea is the input of the innovation process and an implementation project with a proven idea is the output.

The production process of the organization provides the main output of the organization. Workers involved in production processes can be participating in the innovation process during their working hours in order to not disrupt the operation of production processes.

\subsection{Attributes, Roles and Policies of an Innovation Process}

Input into the innovation process is a new idea that is supported by motivational tools in the form of rewards for owners of successfully implemented ideas. Selection and evaluation of new ideas is made by independent evaluators (at least three reviewers) to minimize subjective views on the continuation of the presented idea. After reaching a certain number of points the innovative idea is developed and the manager of innovation administration asks for an approval of a budget required to implement an innovative project. The total budget for innovative projects is set out at the beginning of a financial year so that it can finance innovative projects. Each already implemented project contributes to this budget with their agreed percentage of profits, which can also fully use the results of innovative projects. It is necessary to distinguish the implementation project and an innovative project. The innovative project usually does not strictly keep the rules of project management, as confirmed by Sergey Filipov and Herman Mooi in [3], which indicates that "to specify the idiosyncratic nature of innovative projects as opposed to conventional projects.“

The innovation process can distinguish the following roles:

Innovation manager is the main coordinator of all innovation activities from the submission of an innovative idea through the selection of evaluators to assess the inclusion of an innovative project and its outcomes in the innovation fund. He provides communication with employees on the course of innovation, nominates the members of the commissions, submits proposals for project managers, supervises the running of an innovative information system and prepares quarterly evaluation of the course of innovation activities. It is a role that is constantly busy and for the whole process indispensable.

An innovator submits innovative ideas, formalizes the idea of them in writing into an understandable form for further processing. It is the author of the idea, problem solutions or also the author of implementing regulations (e.g. a project), or he may actively contribute to implementation. The role of an innovator can be received by any employee who actively participates in the presentation of innovative ideas formalized through an innovative portal to which employees are encouraged to submit innovative ideas. 


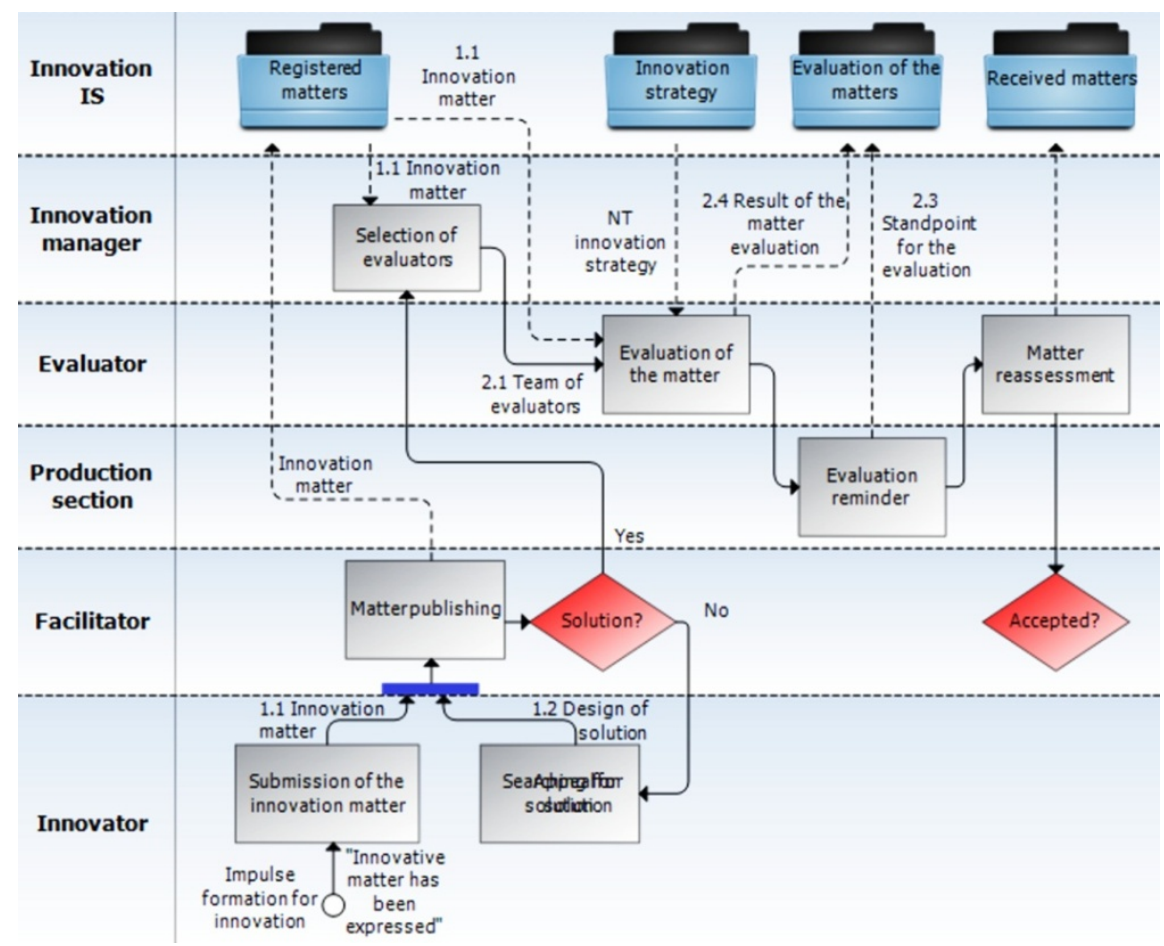

Fig. 3. A process for administrating an innovation idea

A facilitator identifies ideas and supports the authors, to whom he helps to formulate problems or ways of implementing ideas. He may be authorized to represent the innovators (idea authors') in the evaluation process. He informs members of an innovative zone about new innovative ideas, the solutions of the implemented projects and their benefits. He recruits members into the project teams.

An evaluator participates directly in evaluating the innovative proposals. The outcome of an evaluation decides the future of an innovative idea. The evaluator is actively involved in the innovation process and can re-review the idea (after re-submitting, or after specifying details of some parts), or assess the benefits of innovation.

A project leader is the manager of the innovative project after headquarters has authorised the project proposal.

The Production Department is an organizational unit of the company, which uses the result of an innovative project for its commercialization.

An innovative information system is the information system supporting the innovation process. Its main function is to collect ideas and record them during the innovation process to the implementation themselves, creating new business value for future use. It allows you to register ideas, helps to tune these ideas with a company's business strategy, supports the evaluation of ideas, creates a business environment and collaboration systems for both authors and evaluators of ideas, but also for implementation and project teams and communicates information directly to a company's management. 


\subsection{Measuring an Innovation Process}

An open question remains for further research and that is the correct setting for innovation process metrics. If we use only the traditional metrics, such as a number of submitted ideas (inputs into the innovation process) and the number of ideas implemented (as a continuous indicator), so we could get a difficult to read benefit which to the short term point of view brings higher overhead costs without generating an immediate sales value for the company. The ratio of the number of ideas and implemented ideas is also misleading, because there is a question: what's better? If the ratio is close to zero or to one? This ratio cannot be evaluated in this way because the main value is in the quality it brings and then in the future usefulness of the results of the innovative project. Our aim is to clarify the indicators of the innovation process especially in terms of future benefits. However, the current metrics (measurable indicators), which were set only in terms of estimated future value creation are: the number of outputs of the innovative project, the usefulness of the implementation project (using the repeatability of output), the number of identified outcomes as a business opportunity, the number of contracts (signed contracts) transformed from the business opportunities created by innovative outputs, etc. Considering the short term history of operating the innovative zone in the company it is not possible to use values of these metrics and indicators, the results will be published in terms of these indicators later in the future work of our team.

\subsection{Implementation}

Organizational arrangements and the creation of an innovative environment for an innovative zone is the role of top management. To create an environment for innovation and flexible collaboration space the portal solution can be used. Suitable for implementation of the innovation process can be company's portal using Microsoft SharePoint in a particular company's environment. The portal includes features in addition to a normal company's site, which are especially dedicated to the presentation of innovative ideas. The innovator completes his ideas in an innovative corporate portal environment, which is used daily in his work, this is very important in order to minimize barriers when he needs to express innovative ideas.

The following figures bring closer the options for collecting ideas, which are accessible also to unregistered users, or just random visitors to the portal.

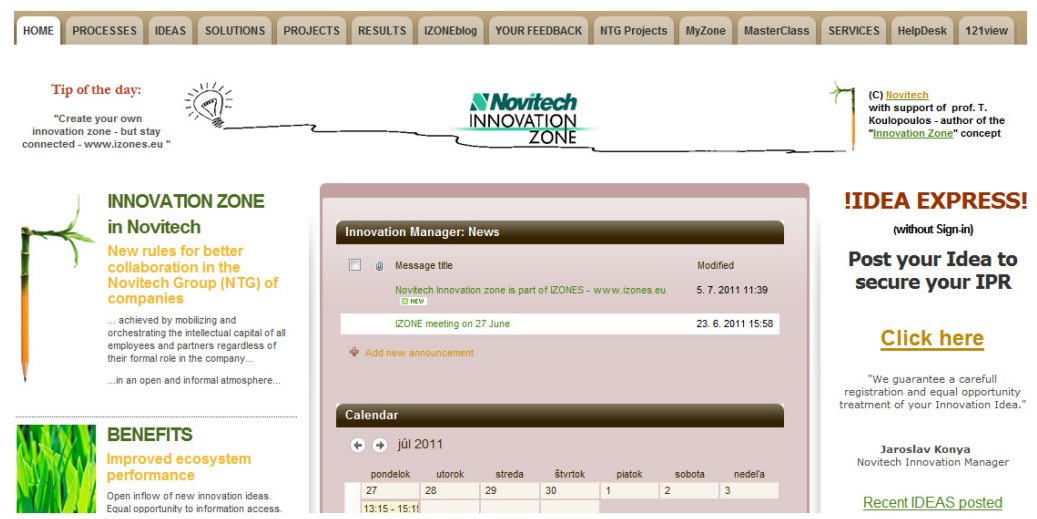

Fig. 4. Company's portal with a possibility to enter ideas without login (for unregistered users) 
Title:

Your name:

Your E-Mail:

Your Innovation Idea:

Idea Implementation:

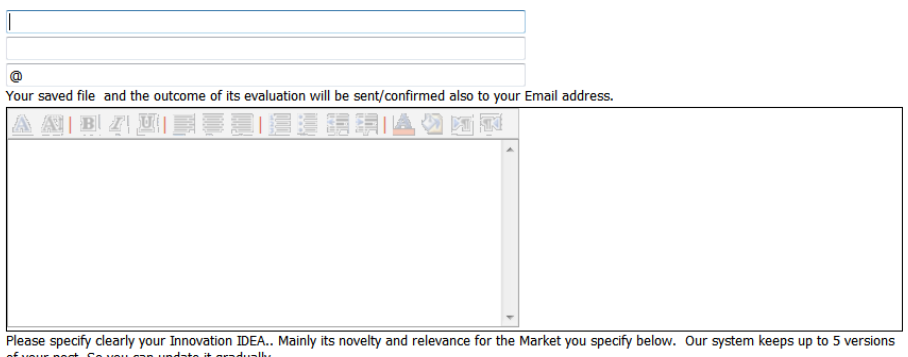

of your post. So you can update it gradually.
ons.

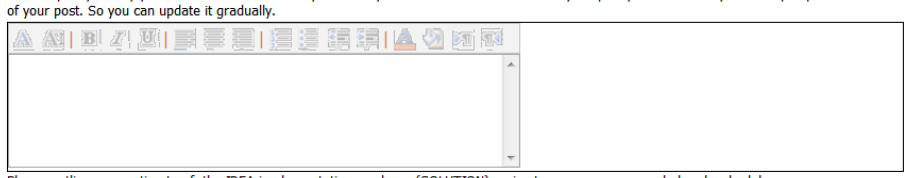

Please outline your estimate of the IDEA implementation roadmap (SOLUTION) main steps, resources needed and schedule.

Fig. 5. A screen used by authors of submitted innovative ideas

The company, which actually operates the portal, maintains the principle of openness and creates a competitive hub provoking to share ideas with their own innovative topic for outsiders. For the internal staff it may create a feeling of uncertainty and fear by ideas coming from outside, but on the other hand, it encourages and leaves no one asleep, because it is in the interest of each employee that he thinks of actions in terms of enhancing the effect of "your" business through his own ideas.

Dear portal Visitors and Partners,

Please have a Preview of Innovation IDEAS submitted via the IDEA EXPRESS channel sorted by Idea Status.
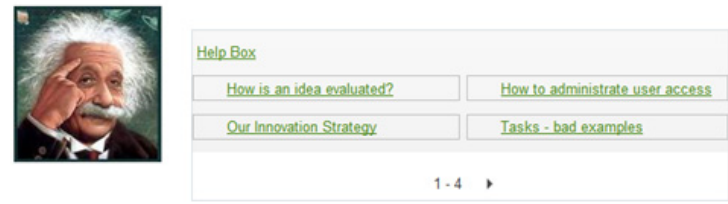

| Back to Recent IDEAS posted |

| Add your IDEA | IDEAS Accepted for Evaluation |

\section{All posted IDEAS}

\begin{tabular}{|c|c|c|c|c|c|c|c|c|c|c|}
\hline \multirow{3}{*}{$\begin{array}{l}\text { ID Created } \quad \text { Your E-Mal } \\
\text { Đidea status : Accepted (22) }\end{array}$} & \multirow[t]{2}{*}{ Your name } & \multirow[t]{2}{*}{ Idea Title } & \multirow[t]{3}{*}{ Market } & (อ) & \multicolumn{3}{|c|}{ Your Skype name } & \multicolumn{2}{|c|}{ Comments } & Modifed \\
\hline & & & & & & & & & & \\
\hline & & & & \multicolumn{7}{|c|}{ IDEA evaluation reports } \\
\hline$\boxplus$ Idea status : Pending (6) & & & & & Q & Evoluation Conclusion & Mark 1 & Mark 2 & Mark 3 & Total Scere \\
\hline Đidea status : Rejected (12) & & & & & 17 & $\begin{array}{l}\text { Irecommend to test this } \\
\text { service with low costs } \\
\text { at the becinning. }\end{array}$ & 4.0 & 3,0 & 3,0 & 10,0 \\
\hline$\boxplus$ Idea status : Updated (4) & & & & & 19 & $\begin{array}{l}\text { Recommend simple and } \\
\text { cheap implementation }\end{array}$ & 4,0 & 3,0 & 3,0 & 10,0 \\
\hline Back to Recent IDEAS posted I & & & & & 40 & $\begin{array}{l}\text { Irecommend vou } \\
\text { molementidea weth } \\
\text { nexpensive solution for } \\
\text { grocessing voise cals } \\
\text { driven by process } \\
\text { solution. }\end{array}$ & 4,0 & 3,0 & 4,0 & 11,0 \\
\hline
\end{tabular}

Fig. 6. Overview of all innovative ideas and the webpart Idea evaluation report from the idea evaluators 


\section{Conclusion}

The presented attempt to create an innovative zone and implement innovation in a business environment has the ambition to eliminate the above mentioned obstacles and to verify the viability of a reference model for an innovative zone in a company. For the first quarter of year of the operation of the innovative zone over 70 new ideas were recorded of which 4 have been implemented and another 10 were approved for implementation. Compared with the previous period of time when new ideas were very rarely introduced, or perhaps even in greater numbers, but with not enough determination and self motivation, and implementation was doomed to failure, because neither the environment and culture in a company was ready for developing the innovative ideas. It was not necessary because the company's operation was secured by long-term contracts, which are now being converted to the short-term. The aim of creating the innovative zone is to enhance the creative potential of employees involved in creating new ideas in line with a company's strategy and thus increase the chances of the company to compete on the market, due to the higher number of transformed ideas into real verification and outputs, respectively. A company will form a reservoir of knowledge and experience of practical verifications, which can be a benefit for the company either by direct trade with the results or their application in specific projects in different forms of benefits (reducing the development cycle of a new product, a cheaper product development, fewer resources required to implement a project or product delivery). With this verification of the reference model the innovation process can be applied in other companies, where this is in line with the company's strategy and the willingness of management of companies to accelerate their capital in favor of the mental agility of the company's future.

Acknowledgments. This work was supported by grant KEGA No. 021TUKE-4/2012 (65\%), the project Development of Centre of Information and Communication Technologies for Knowledge Systems (26220120030) supported by research and development operational program financed by the ERDF $(25 \%)$ and the CP-IP 214657-2 FutureSME, (Future Industrial Model for SMEs), EU project of the 7FP in the NMP area (10\%). The team also thanks Novitech Company for a willingness, which allowed us to examine conditions for implementation of innovation zones in the real business environment, especially thank the President and Chairman of the Board (Chairman of the Board of Directors), Dr. Attila Toth, for his inspiring advice and transfer of experience to us.

\section{References}

1. IPA Independent Project Analysis Ltd., http: / / www . ipaglobal . com

2. Mann, D.: Hands-on Systematic Innovation. CREAX Press, Belgium (2002)

3. CREAX Innovation Suite, http: / / www . creax. com

4. Filipov, S., Mooi, H.: Innovation Project Management. Journal on Innovation and Sustainability 1(1) (2010) ISSN 2179-3565 
5. Koulopoulos, T.M.: The Innovation Zone. Published by davies-Black Publishing, a division of CPP, Inc., Mountain View (2009) ISBN 978-0-89106-234-9

6. Révészová, L., Pal'ová, D.: Basics of modeling business processes, 1st edn. Technical University of Košice (2009) (in Slovak) ISBN 978-80-553-0174-7

7. Hrnčiar, M.: Analyze of processes, services with the use of approaches of ISO/IEC 15504. In: International Scientific Conference on Diagnostics of the Company, Controlling and Logistics III, pp. 81-84. University of Žilina (2006) (in Slovak) ISBN 80-8070-527-5

8. Repa, V.: Business processes, Process control and modeling, 2nd edn. Grada Publishing, Praha (2007) (in Czech) ISBN 978-80-247-2252-8

9. Zolotová, I., Kubičko, P., Landryová, L., Hošák, R.: A design of a reference model of an innovation process and its implementation in business using an innovation zone. In: APMS 2011 International Conference on Advances in Production Management Systems, September 26-28, pp. 1-9. Stavanger, Norway (2011) ISBN 978-82-7644-461-2

10. Innovation zone in Novitech, http: / / izone.novitech.sk/default.aspx 